\title{
The Use of Product Life Cycle Assessment Technology to Achieve Product Sustainability
}

\author{
Muhammad Aliwi Kanoa, Prof. Dr. Manal Jabbar Sorour \\ Baghdad University - College of Management and Economics
}

DOI: $10.37648 / \mathrm{ijrssh.v10i03.035}$

Received: 30 ${ }^{\text {th }}$ June, 2020; Accepted:28th July, 2020; Published: 22ndAugust,2020

\begin{abstract}
This research aims to demonstrate the knowledge pillars of the product life cycle assessment technique and how to measure the cost according to this technique, and to clarify its role in reducing costs, improving product quality and optimizing the use of available resources, and a set of results has been reached, the most important of which are: The separation of environmental costs through the use of product life cycle assessment technique helps the Management in handling the increase of these costs, reducing the rates of environmental pollution and preserving resources, which contributes to achieving the sustainability of the product, and based on the results obtained, a set of recommendations were presented, the most important of which were: The government shall encourage economic units in their endeavor to reduce environmental impacts and optimal exploitation of available energy and resources, through the provision of subsidies and tax exemptions.

Keywords: environmental management accounting, environmental costs, product life cycle assessment, product sustainability.
\end{abstract}

\section{INTRODUCTION:}

The interest in environmental issues and its problems has clearly increased in recent times, as a result of many pressures and motives, including misuse of natural resources, thermal emissions, radiations and pollutants, high product costs, and the increasing demand of stakeholders that economic units adhere to taking care of environmental issues and the harmful effects that they can cause to the surrounding environment and community.

The economic units faced new requirements, including responding to environmental laws and regulations, obtaining detailed information on environmental performance, evaluating products and operations from an environmental perspective, and conducting knowledge exchange internally and externally from an environmental perspective, and therefore there are deficiencies in traditional management accounting tools, and they need reconfigure its tools to suit the environmental concerns of economic units, through the use of environmental management accounting techniques, which contributes to providing the information that the administration needs to identify opportunities for cost reduction and optimal exploitation of resources, energy and other environmental opportunities to achieve the sustainability of its products.

\section{FIRST SECTION: RESEARCH METHODOLOGY AND LITERATURE REVIEW}

\section{Research Methodology}

\section{First: Research Problem}

The global openness of the markets has led to large numbers of foreign products at low prices compared to local products, which have exposed Iraqi economic units to many pressures for various reasons, the most important of which is the high cost of their products and the low level of their quality, which requires the search for 
solutions that lead to rebalancing between the responsibilities that fall on the shoulders of the economic units, to reduce environmental pollution and reduce waste, and rationalize the use of resources and energy, and thus reduce costs in order to provide sustainable and environmentally friendly products capable of competing with foreign products in terms of price and quality, and thus achieve customer satisfaction.

In light of this, the research problem is embodied through the following questions:

1. Does measuring the cost of products according to the product life cycle assessment technique contribute to providing the necessary information to address the environmental impacts?

2. Does the use of the product life cycle assessment technique contribute to providing high quality, environmentally friendly products and achieve product sustainability?

\section{Second: Research hypothesis}

The research is based on a basic hypothesis that:

"Cost measurement according to the product life cycle assessment technique helps to achieve product sustainability".

\section{Third: Research Objectives}

The research objectives can be defined as follows:

1. Explaining the knowledge pillars of the product life cycle assessment technique and how to measure the cost according to this technology.

2. Clarifying the role of this technology in reducing costs, improving product quality and optimizing the utilization of available resources, which would contribute to achieving product sustainability.

\section{Fourth: Research Importance}

The importance of research can be clarified as follows:

1. The use of product life-cycle assessment technology can contribute to reducing costs, improving product quality to meet the expectations and needs of customers, and providing appropriate information at the right time to assist the Management in carrying out its functions, which makes it capable of facing the changes and challenges in the modern manufacturing environment.

2. The great importance of the issue of product sustainability, which has become one of the necessary requirements at the present time as a result of the environmental pollution caused by economic units, in addition to the misuse of natural resources, which led to their decline, and thus will lead to the deprivation of future generations of them.

Literature review: Some foreign studies related to the research topic will be presented as follows:

1. A study of (Held et al, 2018), entitled:

Current challenges for sustainable product development in the German automotivesector: A survey based status assessment.

The purpose of this study is to evaluate the process of sustainable product development and try to increase knowledge regarding how to overcome the consequences and enhance awareness of sustainability, as well as provide insights about the currently used methodology that may serve as a basis for future research. I have reached many results, including that the ability of companies to understand sustainability is crucial to the success of its implementation, as sustainability should be within the general structure of the company through central responsibility and the broad integration of all parts of the company and its employees, as well as focus on the three aspects of product sustainability (economic, environmental and social).

2. A study of (Abbass et al, 2019), entitled:

A Systematic Literature Review on Sustainable Production Indicators to Assess the Sustainable Performance of Industries

The study aimed to analyze the various frameworks of sustainable products to determine the elements and components of those frameworks, as well as to understand the integration of sustainable performance in manufacturing companies, as the scientific literature related to sustainable products was reviewed, and the results indicated that proposals related to sustainable product indicators should be more detailed to include all the pillars Sustainable development. She also indicated that the two techniques of product life cycle cost and material flow cost accounting are the most reliable techniques regarding the subject of sustainable product, and these techniques help to enhance managers' awareness of different frameworks for achieving product sustainability.

3. A study of (Zhou et al, 2019), entitled: Life Cycle Comparison of Greenhouse Gas Emissions and Water Consumption for Coal and Oil Shale to Liquid Fuels

The aim of the study is to conduct a comparative analysis between coal to liquid fuels (CTF) and shale oil to liquid fuels (STF), from the perspective of the life cycle of greenhouse gas emissions and water consumption. The 
study concluded that the emissions of greenhouse gases resulting from the life cycle of CTF and STF are (15.54) and (9.82) tons of $\mathrm{CO} 2$ equivalent/tons of fuel, which is much higher than oil to liquid fuels (OTF) (6.36) tons of $\mathrm{CO} 2$ equivalent/tons of fuel, and the water consumption for the life cycle of the CTF path it is the largest (12.98 tons/ton of fuel, followed by the path of (STF 7.69 track) tons/tonof fuel, and the path of OTF1.18) ton/ton of fuel.

4. A study of (Muza, 2018), entitled:

An Assessment of the Relevance of Environmental Management Accounting for Sustainability in Zimbabwe's Extractive Industries

The aim of this study is to assess the current and potential suitability of environmental management accounting in the mining and extractive industries sector in Zimbabwe, and the study concluded that environmental management accounting contributes positively to the mining sector, thus enhancing sustainability through the three pillars of sustainable development.

\section{SECOND SECTION: KNOWLEDGE PILLARS OF THE PRODUCT LIFE CYCLE ASSESSMENT TECHNIQUE}

The product life cycle assessment technique is one of the environmental management accounting techniques, and before presenting the knowledge foundations for this technology, it is necessary to address the development of environmental management accounting, the nature of its information, and the environmental costs and their types as follows:

\section{First: Evolution of environmental management accounting}

Due to the increase in population growth and industrial development in the twenty-first century, the global economy is growing rapidly, and although this has great economic and social benefits, the manufacturing processes have consumed a lot of resources and energy and made environmental degradation more dangerous, causing pollution of land, water and air. As a result, many stakeholders such as shareholders, customers, employees, suppliers and governments have become increasingly concerned with environmental problems, as the increasing evidence shows that these environmental problems were largely caused by industrial economic units, and thus many economic units face pressure to take measures to control the negative effects of operational activities on the environment, and providing the necessary information about it to meet the needs of external and internal users (Ali et al, 2019: 1)

The traditional financial and cost accounting failed to provide environmental information, especially information related to environmental costs, as many researchers concluded that traditional accounting systems lack recognition of the impact of the environment, so a new field in accounting has emerged called environmental management accounting that works to reduce environmental risks, impacts and costs (Wang et al, 2019: 233). Environmental management accounting techniques, including product life cycle assessment, have been used specifically to assist economic units in managing natural resources and energy and reducing pollution, and the efficiency of resource use for the sustainability of the product (Burritt et al. , 2019).

Environmental management accounting is defined as identifying, allocating, providing and using environmental, material and monetary information, to support decision-making in order to achieve product sustainability (San et al, 2018: 210), as well as managing environmental and economic performance through the development and implementation of appropriate accounting systems and practices related to the environment. In improving environmental performance, especially with regard to managing carbon emissions and energy consumption, to achieve product sustainability, it may also enhance accountability for environmental impacts, and usually includes techniques such as life cycle costs, total cost accounting, product life cycle assessment (Gibassier \& Alcouffe, 2018:1). Also, it is the process of collecting and analyzing financial and non-financial information, which enables the management to make better decisions regarding the optimal use of resources and energy and the promotion of environmental-related activities (Chathurangani \& Madhusanka, 2019:2).

The researchers believe that in light of the recent developments in the industrial environment, and as a result of the increase in the number of economic units and the diversity of their products, especially those products that have a significant impact on the environment such as tire manufacturing and construction industries, which led to a decrease in natural resources and energy and an increase in environmental pollution rates, and so on. This was accompanied by constant pressures by stakeholders for the purpose of reporting environmental impacts, and the lack of traditional accounting systems to determine environmental costs led to the emergence of environmental management accounting that helps reduce the impact of environmental pollution, rationalizing the exploitation of natural resources and energy, which leads 
to reducing environmental costs in order to achieve product sustainability.

Second: Nature of Environmental Management Accounting Information:

The application of environmental management accounting requires the provision of data not only at the monetary level, but also at the physical level in order to measure environmental costs and identify opportunities for reducing environmental risks and impact in order to reduce waste and emissions and consume resources and energy efficiently, thus achieving cost savings and product sustainability accordingly.

There are two types of environmental management accounting information, namely:

1. Information about Physical Environmental Management Accounting (PEMA) (Qualitative):

This information shows how much of the material purchased was actually used in production, and how much of it was actually used as waste, wastewater, or air emissions (Keit, 2011: 11), which is the measurement and recording of actual inputs of materials, energy and water, and outputs from products, waste and emissions that are generated during the manufacture of products, such as the total amount of water consumed, the volume of waste generated, the amount of materials used, the amount of energy consumed, and this information is used for internal decision-making (Govender, 2016: 22). PEMA focuses on the impact of the economic unit on the nature environment expressed in physical units such as kilograms and hours of work (Muza, 2018: 30).

\section{Information about Monetary Environmental Management Accounting (MEMA):}

It is related to environmental costs and profits which include waste control costs, emissions and environmental research and development costs, sales of scrap and waste, and recycling subsidies (Mokhtar, 2015: 61), which is a subsystem of environmental management accounting that deals with financial implications. Of environmental performance, and provides management with the ability to better evaluate the financial aspects of products (Govender, 2016: 25).

\section{Third: Environmental costs}

Environmental costs are the internal and external costs related to environmental damage and protection, and include waste and emissions treatment, environmental prevention and management, the value of purchasing materials from unproductive outputs, and processing unproductive outputs, as well as all costs that have a direct financial impact on the economic unit, individuals, society and the environment. Waste is part of the environmental costs, and according to (United Nations, Division for Sustainable Development), waste is all materials, including water and energy, that have been purchased and paid for, but have not been converted into marketable products, and therefore this indicates inefficiency in production. It also includes all noncommodity outputs including solid waste, wastewater and air emissions (Iredele \& Ogunleye, 2018: 3-4).

According to the Environmental Protection Agency (1995), the types of environmental costs incurred by the economic units are: (Keit, 2011: 14), (Duman et al, 2013: 90).

1. Conventional costs: the costs arising from the use of machinery, equipment, raw materials and consumer goods.

2. Hidden costs: The costs that are hidden from managers, such as the initial environmental costs, legal obligations, and voluntary actions, which are incurred before operating the activities of the process or the system, as many economic units consider these costs as expenses in that period and do not give sufficient importance to these costs in its daily business decisions and activities.

3. Image and relationship costs: (although they are measurable), but they are difficult to measure in comparison with other environmental costs, such as annual environmental reporting costs, and relationships with local people.

4. Probable, dependent or approved costs: These are the costs that may arise in the future depending on the environmental impacts, such as the costs of treating and compensating for future accidental damages to the environment (oil spills), and fines and penalties.

5. External costs: They are costs that are not borne by the economic unit directly, but which arise from activities that have harmful effects on the environment. Figure (2) shows the types of environmental costs. 
Figure (1): Types of environmental costs

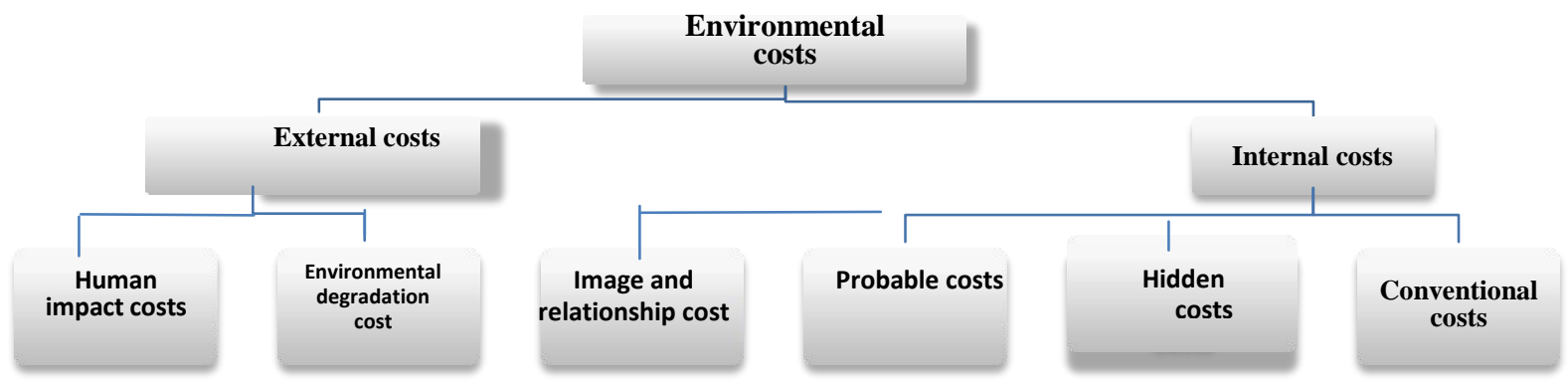

Source:HalukDuman, M. Yılmaż̇çerli, Mehmet Yücenurşen, \& İbrahim Apak, (2013),

The two researchers believe that it has become increasingly clear that determining the environmental costs related to the product, work, or services, and recognizing them in accounting for the economic unit, is necessary for the purpose of making correct decisions, and the environmental costs represent the total costs that the economic unit bears, voluntarily or as a result of legal settlements. To protect, rehabilitate or treat the damages resulting from the impact of the economic unit on the environment, and therefore they are internal costs that have a direct impact on the economic unit and are under its control, and external costs that occur as a result of its activities that affect society and the environment within which the economic unit operates.

\section{Fourth: Life Cycle Assessment Technology (LCA)}

The life cycle assessment is a standardized behavioral method for analyzing the environmental risks associated with the product/process throughout the life cycle, and it is one of the most important and advanced environmental management accounting tools, as it is widely used to compare alternative processes, through analyzing the product life cycle starting from the extraction of raw materials to their final disposal, By evaluating the process, it is possible to identify the hotspots and thus can prioritize the investment and activities necessary to improve its environmental performance, and the life cycle assessment allows a comparison of technology in terms of environmental burden, which provides a clear vision of what will be the impact of environmental performance (Duanet al, 2018: 9).

The life cycle assessment also provides a comprehensive approach to fully assess the environmental impacts of the production process, thus it helps to provide extensive data on the environmental and economic impacts in relation to resource and energy depletion, water use, toxic substances and greenhouse gas emissions, allowing for sound decision-making. These adverse effects result from the processes that occur during all stages of the product life cycle, as the lack of data related to determining the actual costs and impacts leads to uncertainty in the assessment. Therefore, the use of (LCA) technology will help in identifying potential opportunities and areas for improvement and making appropriate decisions to address these harmful effects: Muthukumarana et al, 2018 (2-3), and thus it is a tool that allows to assess the potential environmental aspects and impacts of all stages of the product life cycle (Barros et al, 2019: 2).

LCA includes four phases: definition of goal and scope, inventory analysis, impact assessment, and interpretation (Fauzi et al, 2019: 2), as follows: (Valente et al, 2018: 5), (Zhou et al, 2019: 75-76). ), (Corti et al, 2019; 84)

\section{Stage 1: Goal and Scope}

It specifies the reason for conducting a life-cycle assessment, possible applications, and other preliminary elements necessary as a basis for the study, such as functional unit, system boundaries, or assignment procedure.

\section{Stage 2: Life Cycle Inventory Analysis}

In this stage, the material inputs and outputs are calculated in the sense of the resources that enter such as raw materials, auxiliary materials and energy, and those that leave the system such as emissions, waste and products through the collection of data on consumption of life cycle resources, emissions and wastes to be identified and quantified, and this includes data collection, calculation, standardization and verification. As the reliability and accuracy of inventory data is directly related to the accuracy of the results of the third-stage analysis, it is necessary to collect, standardize and modify relevant data several times to meet the system reliability requirements. 


\section{Stage 3: Life Cycle Impact Assessment}

This stage aims to analyze life-cycle energy consumption, greenhouse gas emissions, water consumption and calculate potential impacts on the environment, including:

1. Choosing impact categories, indicators and characterization models.

2. Classification to link impact categories and inventory data.

Figure (1)

Stages of product life cycle assessment

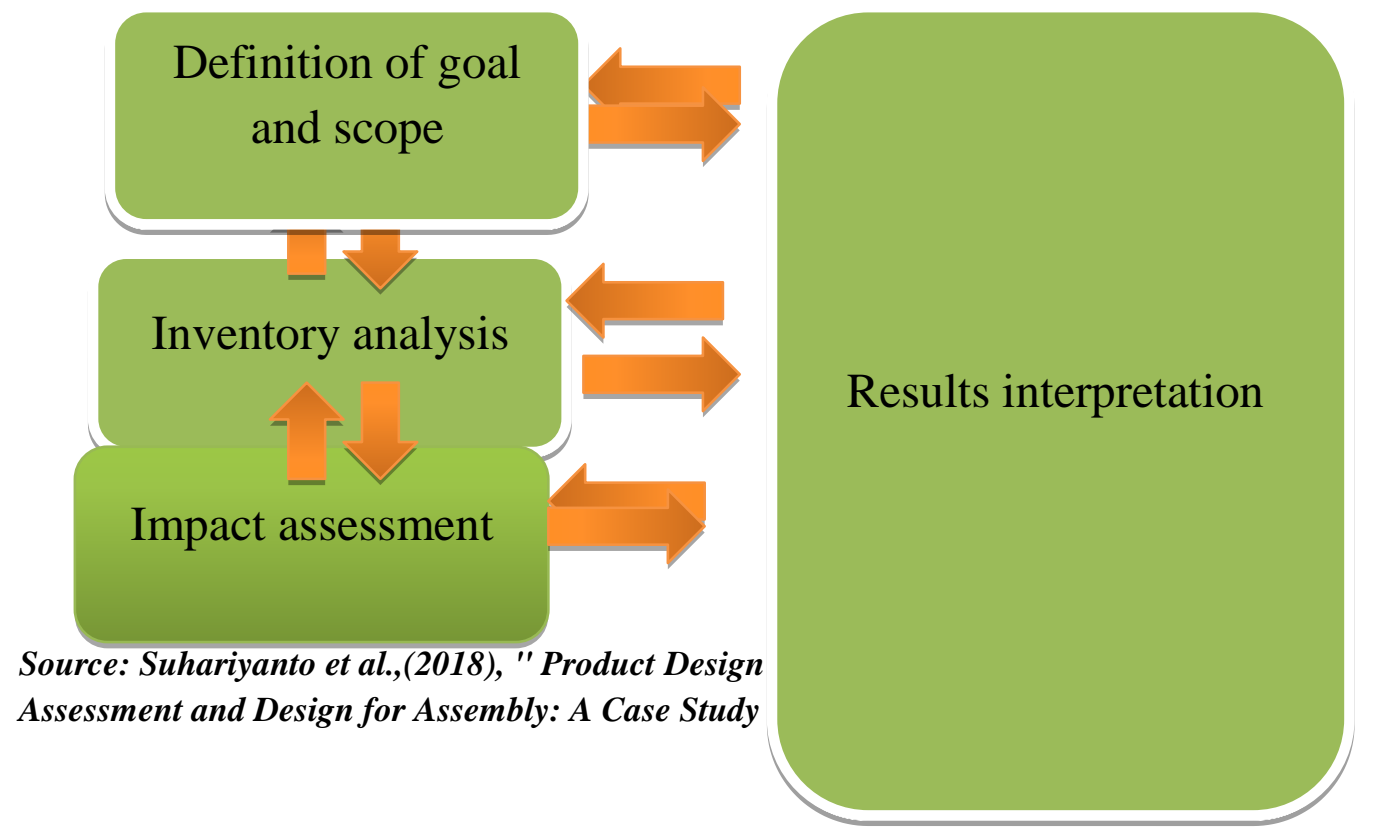

The two researchers believe that the product life cycle assessment technique is one of the techniques of environmental management accounting, which studies the environmental effects of the product or activity throughout its entire life cycle, from the acquisition of raw materials to their disposal and it is called life cycle analysis, as the materials used and the disposal of energy and waste are identified and measured and their impacts on the environment are assessed, as well as assessing improvement opportunities, which in turn provide opportunities to reduce environmental pollution, better use of resources and energy, which contribute to improving quality, reducing costs, and improving environmental and economic performance.
3. Description for calculating the values of the

\section{Stage 4: Life Cycle Interpretation}

During this stage, the results of the life cycle analysis are interpreted, to provide many useful conclusions and to draw a series of recommendations according to the aim and scope of the study, and to define improvement strategies through evaluating the results, Figure (2) shows the stages of product life cycle assessment. category indicators.

\section{Results interpretation}

THIRD SECTION: PRODUCT SUSTAINABILITY AND THE ROLE OF PRODUCT LIFE CYCLE ASSESSMENT TECHNOLOGY IN ACHIEVING IT

\section{First: Products Sustainability}

A sustainable product is a product that does not have significant negative impacts on environmental and social systems, and this includes not only the use phase, but also the effects of raw materials, the production chain, the supply chain, the use phase, and finally the end of the shelf life, as the development of sustainable products requires consideration of the entire product life cycle. The sustainable product is often evaluated in terms of greenhouse gas emissions, energy efficiency, or environmental pollution (Kammerl et al, 2017: 25-26), and product sustainability (PS) examines how the products can provide economic benefits for units at the same time they provide environmental and social benefits to society in general (Dyllick \& Rost, 2017: 347).

The stages of the sustainable product life cycle include design, production, marketing, distribution, use and 
disposal, and the following are an illustration of these stages:

\section{Sustainable product design}

Manufactured products affect all aspects of sustainability (economy, environment and society) throughout their life cycle, such as using materials, manufacturing, marketing, use and disposal. It has been found that about $80 \%$ of the sustainability impacts are identified in the design stage, and therefore this stage is considered an important strategy to achieve product sustainability that is defined as the product's ability to operate continuously while ensuring the lowest level of environmental impacts and providing economic and social benefits to stakeholders, the three aspects of sustainability should be considered an integral part of sustainable design (Ahmad et al, 2018: 49). The product life cycle, as an analytical tool for assessing design alternatives, the performance of environmental innovations and tracking design processes (Gutierrez et al, 2019: 2).

\section{Sustainable Manufacturing}

Manufacturing is indispensable in modern society because of its vital role in terms of community service, and the pivotal role in contributing to the national and global economy, yet at the same time the systems of human activity together consume a large amount of resources and generate waste and emissions, which affects the environment and society. As the current production and consumption patterns are seen to be largely responsible for the shortage of resources and the degradation in the environment, and as a result, industrialization is developing within the framework of the requirements of the three aspects of sustainability (environment, economy and society) (Hussain \& Jahanzaib, 2018: 237). The product life cycle assessment technique has been successfully applied in several industrial economic units to optimize manufacturing processes (Behnami et al, 2019: 4).

\section{Sustainable Marketing}

In the literature, concepts such as environmental marketing, green marketing and sustainable marketing are used synonymously, which has been defined as all studies related to the positive or negative effects of marketing activities on environmental pollution, energy consumption and other resources or as marketing activities that attempt to reduce the environmental and social impacts of existing products and production systems. It includes the promotion of less harmful goods to meet the needs of society and consumers (Kibrit, 2019:9), as it is defined as the process of management responsible for identifying, anticipating and meeting the requirements of customers and society in a profitable and sustainable manner (Goyal et al, 2018: 62).

\section{Product use}

It is related to the period of time in which the product is used by the customer, as during this stage he may consume auxiliary products such as energy, and therefore the traditional requirements are energy efficiency, safety, reliability, ease of operation, maintenance or repair, and the interaction of the product with the user and consumer behavior strongly affects the sustainable performance of the product in its use phase (Schwarz, 2017: 18).

\section{Sustainable Disposal}

It includes reuse, recycling and final disposal, as reuse refers to the use of various means to extend the practical service life of products by transferring them to new owners with or without prior modification (such as repair), and this is done for example through the secondhand market, as re-use and recycling reduce environmental impacts compared to burning and landfilling of waste. Reuse is more beneficial than recycling (Sandin \& Peters, 2018: 3), while recycling is a procedure for converting waste materials into useful things again, i.e. producing new products from old materials. Recycling is considered an environmentally friendly solution instead of disposing of waste, and things may be used for the same purpose without recycling that usually requires energy consumption, such as selling mineral water again using the same bottles (Toth, 2019: 3 ), and LCA can be used to analyze recycling process, which leads to the goal of reducing costs, increasing efficiency and enhancing sustainability (Huang et al, 2019: 23).

\section{Second: Role of Environmental Management} Accounting in Product Sustainability

There are some motives for integrating sustainability into environmental management accounting practices, including cost reduction and risk management, as resource efficiency and cost saving opportunities can be identified by collecting information on related environmental and social expenditures, and linking them to financial benefits and environmental and social performance, such as use controlling use and energy costs across the economic unit which is the first step towards reducing and improving efficiency, and therefore management accounting can provide a useful internal reporting tool to track progress and show how environmental and social external costs decline over time with a commitment to sustainability, because the leading units now realize that their long-term future is closely related to their environmental performance. On the other hand, there is increasing pressure to manage and report non-financial risks. Therefore, a risk management and reduction strategy can benefit from identifying social and 
environmental risks associated with current financial performance (by using external costs as indicators of risk). Without adequate and appropriate systems to define such Costs are calculated, the units may not able to meet the future expectations of stakeholders. The literature discussing the relationship between economic and environmental performance and environmental efficiency shows that in order to improve environmental performance while enjoying economic benefits, economic units need to be innovative and sensitive to the environment, and to be able to integrate information. Environmental management in its business strategies, so it needs an appropriate information system to provide such information for administrative decision-making, and for this, environmental management accounting can play an important role in any economic unit by integrating all basic functions and providing relevant information for decision-making (Agada, 2018: 71-72).

Muza (2018) believes that environmental management accounting (EMA) generally contributes to enhancing sustainability, by implementing environmental management accounting techniques, including product life-cycle assessment, which is a strong indicator for achieving product sustainability, as the great attention to environmental considerations improves environmental efficiency, As well as the economic and social performance (Muza, 2018: 241).

Therefore, the use of environmental management accounting techniques such as assessing the product life cycle contributes to providing material and monetary information, which helps in reducing the rates of environmental pollution and preserving resources, through the sustainable use of water, energy and materials, and reducing the environmental impacts of products during the entire life cycle, thus reducing costs to achieve product sustainability, and this proves the research hypothesis (Cost measurement based on the product life cycle assessment technique helps to achieve product sustainability).

\section{FOURTH SECTION: CONCLUSIONS AND RECOMMENDATIONS}

First: Conclusions: The research concluded with a set of conclusions, namely:

1. There is a lack of knowledge of accountants on how to define and allocate environmental costs and revenues, just as some environmental costs are not recorded in the records and environmental issues are not integrated into existing accounting systems and practices.
2. The use of product life cycle assessment technology contributes to reducing waste and emissions, rates of environmental pollution, and moving towards optimal utilization of available energy and resources, thus reducing product costs and improving their quality.

3. The sustainability of products requires the development of mechanisms that ensure the reduction of environmental impacts, taking into account the economic and social aspects, in all stages of their life cycle, from planning and design to disposal, reuse or recycling.

4. The disposal of products at the end of their productive life through recycling and reuse contributes to reducing environmental impacts and improving economic performance, but for the sake of re-use and recycling, it should be taken into consideration in the design stage and the requirements for efficient and effective construction and development of ideas.

5. Separating the environmental costs through the use of the product life cycle assessment technique helps the management in dealing with the high costs and provides the necessary information to reduce the rates of environmental pollution and waste, which contributes to achieving the sustainability of the product.

Second: Recommendations: In light of the conclusions, the researcher recommends the following:

1. The government's claim to the economic units of the necessity to provide environmental accounts parallel to the financial accounts, which requires rebuilding the accounting systems to take into account environmental and social issues.

2. Preparing accounting cadres by involving them in training courses on how to use the technique of evaluating the product life cycle, and how to provide material and monetary information to management to enable it to perform its multiple functions.

3. The government should encourage economic units in their endeavor to reduce environmental impacts and optimal utilization of available energy and resources, by providing subsidies and tax exemptions.

4. The necessity of working to increase awareness of environmental and social issues by raising issues related to the environment in periodicals, television and conferences, which constitutes a fundamental pressure on managing economic units to improve their environmental performance. 


\section{REFERENCES:}

1. Abbass , N. M., Rahman , A.A ., Aziz , Y .A ., Sidek , S., (2019)," A Systematic Literature Review on Sustainable Production Indicators to Assess the Sustainable Performance of Industries " ,International Journal of Academic Research in Business and Social Sciences, Vol .(9), No. (2),PP. 497 - 515.

2. Agada , Alfred ., (2018), " The Role of Management Accountants in Accounting for Sustainable Development " , Journal of Business and Management, vol.(20), No. (12),PP. 70-74 .

3. Ahmad, S ., Wong, K ., Tseng, M ., Wong, W .,(2018), " Sustainable product design and development: A review of tools, applications and research prospects " , Resources, Conservation \& Recycling Journal , 132 , 49-61.

4. Babader, A .,Ren, J., Jones, K ., Wang, J ., (2016), " A system dynamics approach for enhancing social behaviours regarding the reuse of packaging " , Journal of Expert Systems with Applications , vol.46, pp. 1-21.

5. BERKSOY , B ., (2018) , " SÜRDÜRÜLEBILIIRLIKK VE ENTEGRE RAPORLAMA METODOLOJISININ SEKTÖREL BAZDA KARŞILAŞTIRMALI DEĞERLENDİIILMESI ～" ， IşıÜniversitesi , SosyalBilimlerEnstitüsü'neLisans (MA) .

6. Burritt , R. L ., Herzig , C ., Schaltegger, S ., Viere , T ., (2019), "Diffusion of environmental management accounting for cleaner production : evidence from some case studies" , Journal of Cleaner Production ,Vol. (3), No. (2).

7. Dogu , F. U ., Aras , L ., (2019), " Measuring Social Sustainability with the Developed MCSA Model: Güzelyurt Case ", sustainability journal , 11, 1-20.

8. Duman , H .,̧̇çerli , M .,Yücenurşen, M .,Apak, İbrahim ., (2013), " Environmental cost management within the sustainable business", The Online Journal of Science and Technology, Vol . (3), Issue (2).

9. Dyllick , T .,Rost , Z ., (2017), " Towards true product sustainability " , Journal of Cleaner Production , vol. 162, pp. 346-360.

10. Erokhin, V.,Endovitsky, D .,Bobryshev , A .,Kulagina, N .,Ivolga , A .,(2019), "Management Accounting Change as a Sustainable Economic Development Strategy during Pre-Recession and Recession Periods: Evidence from Russia" , Journal of sustainability, Vol . (11), No.(11).

11. Goyal, A. P.,Bansal , S .,Srivastava , S .,(2018), " SENSORY MARKETING: PERSPECTIVES ON BENEFITS CONSUMERS' GRAPPLE IN CHOOSING GREENER PRODUCTS " , Global Journal of Commerce and Management Perspective, Vol . (7), No. (2) .

12. Gutiérrez , M. J. Á ., Gómez , A. M ., González , F. A., (2019) , " Standardization Framework for Sustainability from Circular Economy 4.0" , Journal of sustainability , 11, PP. 1-26.

13. Huang, J ., Zhao , R ., Huang, T., Wang, X ., Tseng, M.L., (2018)," Sustainable Municipal Solid Waste Disposal in the Belt and Road Initiative: A Preliminary Proposal for Chengdu City" , Journal of sustainability ,10(4) .

14. Hussain, S.,Jahanzaib, M ., (2018), "Sustainable manufacturing - An overview and a conceptual framework for continuous transformation and competitiveness ", journal of Advances in Production Engineering \& Management, Vol. (13), No. (3).

15. Iredele , O.O, Ogunleye , O . J ., (2018)," An Evaluation of Environmental Management Accounting (EMA) Practices and Barriers to its implementation : A comparative study of Nigeria and south Africa ", crawford Journal of Business \& Social Sciences, Vol . (13), No.( 1 ).

16. Kaiser, M, (2017), " The suitability of Environment Management Accounting (EMA) models applied by the German Mittelstand " , PhD thesis of Philosophy in the Business Schoolthe University of Gloucestershire .

17. Kammerl , D .,Schockenhoff , D.,Hollauer , C .,Weidmann , D .,Lindemann , U.,( 2017)," A Framework for Sustainable Product Development ", Sustainability Through Innovation in Product Life Cycle Design , pp21-32.

18. KAYIKÇI , P., ARMAĞAN , K ., DAL , N ., (2019), "SürdürülebilirPazarlama: KavramsalBirÇalışma", journal of Bucak faculty of business, Vol. (2), No. (1). 
19. Keit, T ., (2011), " The application of Environmental Management Accounting amongst KwaZulu-Natal's Top Businesses " , Graduate School of Business Faculty of Management Studies .

20. Liu, X .,Schraven , D .,Bruijne , M ., Jong, M .,Hertogh , M ., (2019), "Navigating Transitions for Sustainable Infrastructures-The Case of a New High-Speed Railway Station in Jingmen, China", sustainability journal , 8 , 1 21.

21. Mokhtar , N . B ., (2015), " The extent of environmental management accounting (EMA) implementation and Environmental Reporting (ER) practices: evidence 